\title{
Characteristics of eyes with secondary loss of visual acuity receiving variable dosing ranibizumab for neovascular age-related macular degeneration
}

\author{
Alessandro Mariani • Angeliki Deli • Aude Ambresin • \\ Irmela Mantel
}

Received: 22 March 2011 /Revised: 13 May 2011 /Accepted: 16 May 2011 /Published online: 2 July 2011

(C) Springer-Verlag 2011

\begin{abstract}
Purpose The aim of this work is to investigate the characteristics of eyes failing to maintain visual acuity (VA) receiving variable dosing ranibizumab for neovascular age-related macular degeneration (nAMD) after three initial loading doses.

Methods A consecutive series of patients with nAMD, who, after three loading doses of intravitreal ranibizumab ( $0.5 \mathrm{mg}$ each), were re-treated for fluid seen on optical coherence tomography. After exclusion of eyes with previous treatment, follow-up less than 12 months, or missed visits, 99 patients were included in the analysis. The influence of baseline characteristics, initial VA response, and central retinal thickness (CRT) fluctuations on the VA stability from month 3 to month 24 were analyzed using subgroups and multiple regression analyses.

Results Mean follow-up duration was 21.3 months (range 12-40 months, 32 patients followed-up for $\geq 24$ months). Secondary loss of VA (loss of five letters or more) after month 3 was seen in 30 patients (mean VA improvement from baseline +5.8 letters at month 3 , mean loss from baseline -5.3 letters at month 12 and -9.7 at final visit up to month 24), while 69 patients maintained vision (mean gain +8.9 letters at month $3,+10.4$ letters at month 12 , and +12.8 letters at final visit up to month 24 ). Secondary loss of VA was associated with the presence of
\end{abstract}

Electronic supplementary material The online version of this article (doi:10.1007/s00417-011-1734-5) contains supplementary material, which is available to authorized users.

A. Mariani · A. Deli · A. Ambresin · I. Mantel $(\triangle)$

Ophthalmology Department, University of Lausanne,

Jules-Gonin Eye Hospital,

15 Av. de France, Case Postale 133,

1000 Lausanne 7, Switzerland

e-mail: i.mantel.widmer@gmx.ch pigment epithelial detachment (PED) at baseline (p 0.01), but not with baseline fibrosis/atrophy/hemorrhage, CRT fluctuations, or initial VA response. Chart analysis revealed additional individual explanations for the secondary loss of VA, including retinal pigment epithelial tears, progressive fibrosis, and atrophy.

Conclusions Tissue damage due to degeneration of PED, retinal pigment epithelial tears, progressive fibrosis, progressive atrophy, or massive hemorrhage, appears to be relevant in causing secondary loss of VA despite vascular endothelial growth factor suppression. PED at baseline may represent a risk factor.

Keywords Age-related macular degeneration . Anti-VEGF - Ranibizumab - Visual acuity loss . Pigment epithelial detachment

\section{Introduction}

The inhibition of vascular endothelial growth factor A (VEGF-A) has proven to be an effective and safe therapy of neovascular age-related macular degeneration (nAMD) [1-3]. Ranibizumab, a recombinant, humanized, monoclonal antibody fragment, inhibits all biologically active forms of VEGF. Intravitreal injections of this molecule have been investigated in large phase III clinical studies, which resulted in level I evidence of effectiveness and safety of this drug. Monthly injections over the course of 2 years were administered to predominantly classic $[1,2]$, minimally classic, and occult choroidal neovascularization (CNV) [3], and, on average, visual acuity (VA) improved by approximately 1-2 lines, which was highly significant. This mean gain in VA was maintained for over 2 years with monthly injections. 
In the PIER study of three consecutive monthly injections followed by fixed quarterly injections [4, 5], ranibizumab brought about an initial improvement in mean VA, followed by a decline of mean VA thereafter, suggesting that quarterly treatment is inferior to monthly treatment. However, a subgroup of patients did well and maintained their initial VA gain $[5,6]$. The EXCITE study directly compared the results of the PIER quarterly regimen with those of monthly injections [7]. In that study, VA gain decreased slightly with quarterly dosing, but increased slightly with monthly doses of ranibizumab.

In clinical practice, most retina specialists employ a variable dosing regimen based on the results of the PrONTO study [8]. In the PrONTO study, after an initial loading dose of three injections of ranibizumab given once a month, the patients underwent monthly follow-up visits to determine their need for re-treatment. The most common reasons for re-treatment were changes seen on optical coherence tomography (OCT) (recurrent or persistent fluid or increased central retinal thickness [CRT] of $>100 \mu \mathrm{m}$ ) [8]. Although a small and non-comparative study, results of the PrONTO study were highly suggestive that mean VA results comparable to those of the MARINA/ANCHOR study could be achieved with a variable dosing regimen. However, the initial VA gain was not entirely maintained.

A meta-analysis has shown that all variable dosing regimens tend to result in a partial loss of the initial effect, while fixed monthly dosing results in a slight increase in VA after month 3 [6].

The aim of the present study was to investigate the particular characteristics of those eyes with secondary loss of VA that were treated in a routine clinical practice with a variable dosing regimen of ranibizumab according to the principles of the PrONTO study.

\section{Materials and methods}

We report an observational study of a consecutive series of patients with nAMD, who, after the initial 3-monthly loading doses of intravitreal ranibizumab $(0.5 \mathrm{mg}$ each), were re-treated for fluid seen on optical coherence tomography at a single center (University Eye Hospital Jules Gonin, Lausanne, Switzerland) between March 2006 and October 2009. To be included in the analysis, the eye with nAMD had to be treatment-naive before initiation of the ranibizumab treatment, and follow-up duration had to be a minimum of 12 months from initiation of ranibizumab treatment, with monthly visits. A total of 99 patients met the criteria and were included in the study, which was performed in accordance with the tenets of the Declaration of Helsinki for research involving human subjects.
Each patient underwent a baseline assessment of bestcorrected VA (BCVA) measured at $4 \mathrm{~m}$ with standard ETDRS charts, and had an ophthalmic examination that included slit-lamp biomicroscopy, fluorescein angiography (FA), indocyanine angiography (ICG), and OCT (Stratus OCT3, Carl Zeiss Meditec, Inc., Oberkochen, Germany) utilizing six diagonal, slow 6-mm-radial line scans (software version 4.0). The central $1-\mathrm{mm}$ subfield with averaged retinal thickness was used as the CRT. In cases of poor positioning of the fovea and/or false positioning of the automatically set marker lines, the investigator chose one line (with the fovea) and averaged the manual measurement of the fovea and $0.5 \mathrm{~mm}$ from the fovea on both sides.

Initial treatment consisted of three intravitreal injections of ranibizumab (each injection being $0.5 \mathrm{mg}$ ) at monthly intervals; all injections were performed by a retina specialist according to the usual technique.

After the three loading doses, each patient underwent a monthly visit with detailed medical and ocular history, as well as assessment of BCVA, slit-lamp biomicroscopy, fundus biomicroscopy, and OCT; FA was performed at the discretion of the examiner. As a rule, FA was performed in those cases in which loss of VA could not be explained by OCT, if there was a large macular hemorrhage, or if 6 months had passed since the last FA.

Intravitreal ranibizumab injection was discontinued after month 3 (maintenance phase) in eyes that showed an absence of leakage from the CNV on FA, and a dry macula (absence of subretinal fluid and cystic maculopathy) on OCT. Eyes that showed persistent leakage from the CNV on FA and/or fluid in the macula on OCT and/or increased CRT of more than $50 \mu \mathrm{m}$ (compared with smallest previous measurement) and/or new hemorrhage received an additional injection. Pigment epithelial detachment (PED) was not a reason for re-treatment if the overlying retina was dry.

Data collected at each visit included date of the visit, visual acuity (letters correctly identified on an ETDRS chart), CRT (OCT Stratus), and treatment decision (ranibizumab injection or no injection). Missing data from intermediate visits were completed by carrying forward information from the last observation. Baseline characteristics included age, gender, eye, angiographic type of CNV (predominantly classic, minimally classic, occult, or retinal angiomatous proliferation, as determined by a retina specialist), lesion size (disc diameters), presence or absence of PED, and presence or absence of foveal fibrosis/atrophy/ hemorrhage, or hemorrhage covering more than $50 \%$ of the total lesion size.

For data analysis, the statistical program JMP, version 8 (SAS institute Inc., Cary NC, USA), was used. Visual acuity changes were calculated by letters identified on the ETDRS chart. Time intervals were calculated in days (30 days $=1$ month). At the start of the study, a description 
of the patients was obtained, including the number of injections, mean VA, and mean CRT findings. As a second step, the patients were classified into one of two subgroups depending on their VA curves during the variable dosing phase (after month 3): Group A consisted of the "maintainers", defined as those patients who had the same or better BCVA or who had experienced a maximum loss of four letters (less than one line loss on the ETDRS chart) from month 3 until the latest visit between months 12 and 24. Group B consisted of the "losers", those patients who experienced a loss of BCVA of five or more letters from month 3 to the most recent observation. The Wilcoxon/ Kruskal-Wallis test was used to investigate any potential association with the following parameters: initial VA response after the 3-monthly loading doses; difference between the CRT measurements and the thinnest ever measured CRT value of the same patient, averaged over the follow-up period (=mean CRT excess); number of injections per year of follow-up. Fisher's exact test was used for analyzing potential associations with categorical data (presence of PED; presence of fibrosis/atrophy/hemorrhage at baseline).
Because of the somewhat arbitrary threshold between the two groups, the results were verified by a second approach using multiple linear regression analysis.

\section{Results}

The 99 patients included in this study consisted of 32 men and 67 women; the mean age of the patients was 78 years (SD [standard deviation] 8.8 years). Based on baseline FA and ICG, 22 patients presented with predominantly classic $\mathrm{CNV}$, five had minimally classic CNV, 58 had occult CNV, and 14 had retinal angiomatous proliferation. The mean follow-up for all patients was 21.3 months, which ranged from 12 to 40 months. Thirty-two patients completed 24 months of follow-up.

Baseline VA ranged from 0.05 (20 letters) to 0.8 ( 80 letters). Mean VA on ETDRS (Fig. 1a) was 59.2 letters at baseline, but this rose to 66.6 letters $(+7.4$ letters $)$ after the first three injections, then began to drop slightly after month 11 to a level of $64.8(+5.6$ letters $)$ and to $62.6(+3.4$ letters $)$ at months 12 and 24, respectively (number of patients $=99$ and
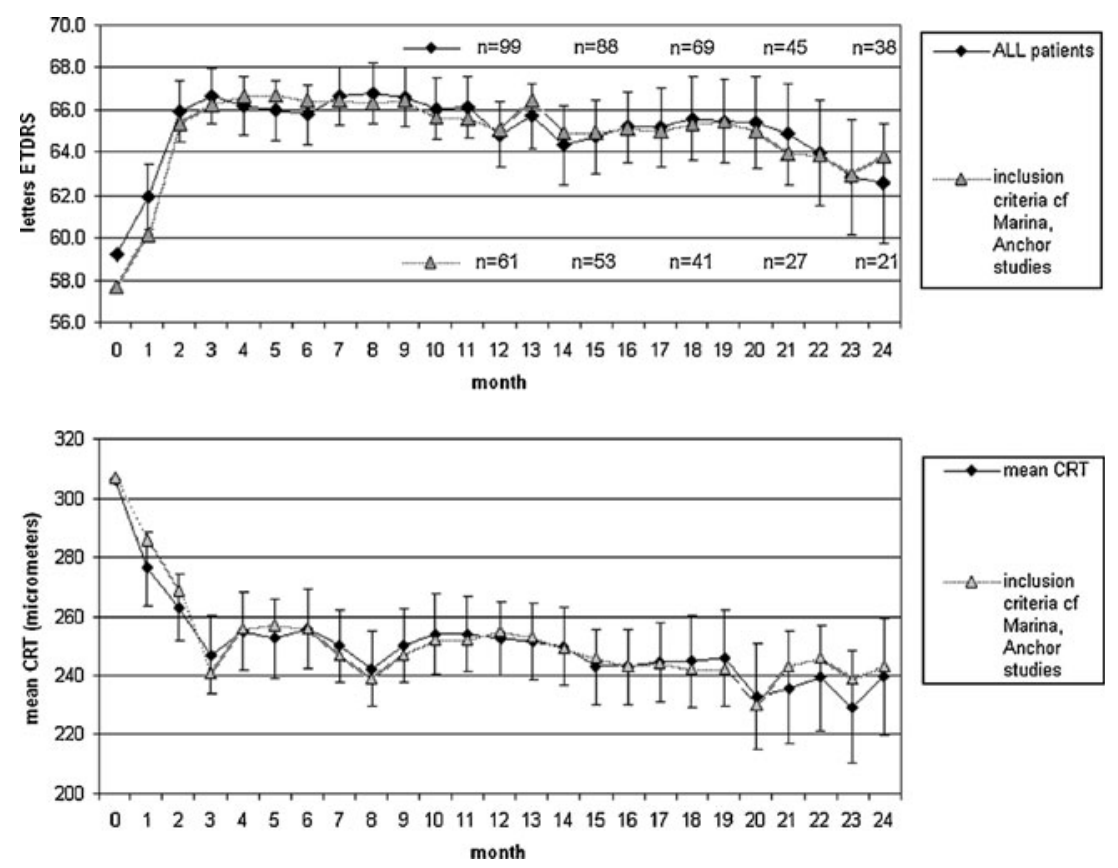

Fig. 1 Mean visual acuity curve and mean central retinal thickness curve of patients with age-related macular degeneration treated with intravitreal ranibizumab. a Mean visual acuity curve (ETDRS letter score) for all included patients treated with variable dosage intravitreal ranibizumab for exudative age-related macular degeneration. Error bars indicate \pm 1 standard error of the mean visual acuity change from baseline. Mean follow-up was 21.3 months (range 12-40 months). The number of patients who completed 12, 15, 18, 21, and 24 months, respectively, are indicated $(n)$. The second curve (without error bars) represents the 61 patients with baseline criteria corresponding to inclusion criteria of the MARINA and ANCHOR studies. b Mean central retinal thickness (CRT) curve in micrometers of mean values for the central subfield on optical coherence tomography measurement for all included patients treated with variable dosage intravitreal ranibizumab for exudative age-related macular degeneration. Error bars indicate \pm 1 standard error of the mean central retinal thickness change from baseline. The second curve (without error bars) are the 61 patients with baseline criteria corresponding to inclusion criteria of the MARINA and ANCHOR studies 
32, respectively). Visual acuity improved by 15 letters or more in 24 and $25 \%$ of the affected eyes by month 12 and month 24 , respectively. It improved by 0 letters or more in $80 \%$ and $70 \%$ of the eyes by month 12 and month 24 , respectively. No more than 15 letters were lost in 94 and $89 \%$ of the eyes by month 12 and month 24, respectively.

Visual acuity response (letter change from baseline) at month 3 was moderately well correlated with the outcome at 12 months (Pearson correlation coefficient $r=0.51, p<0.01$ ), and with the final outcome at up to month $24(r=0.52$, $p<0.01$, Fig. 2). The level of baseline VA showed an insignificant inverse correlation $(r=-0.26)$, and no correlation was found with age $(r=-0.12)$ or with baseline lesion size $(r=-0.09)$.

The mean number of injections was 6.6 per year of follow-up (range, 3-12; SD 1.5).

Mean CRT was $306 \mu \mathrm{m}$ at baseline, but this decreased to $247 \mu \mathrm{m}$ at month 3 and was maintained thereafter (Fig. 1b). Individual CRT fluctuations from month 3 to month 24 , however, resulted in individual differences between the minimal and the maximal value, which ranged between 5 and $238 \mu \mathrm{m}$ (mean, $58 \mu \mathrm{m}$; SD, $39 \mu \mathrm{m}$ ).

Exclusion of the 38 patients whose baseline measurements were outside the criteria of the MARINA and ANCHOR studies did not significantly change the visual acuity outcome or mean CRT outcome at any time point (Fig. 1a and b).

Separating the patients into subgroups A and B, differentiating between those who "maintained" VA after month 3 and those who "lost" VA after month 3 (described in the "Materials and methods" section), revealed that 69

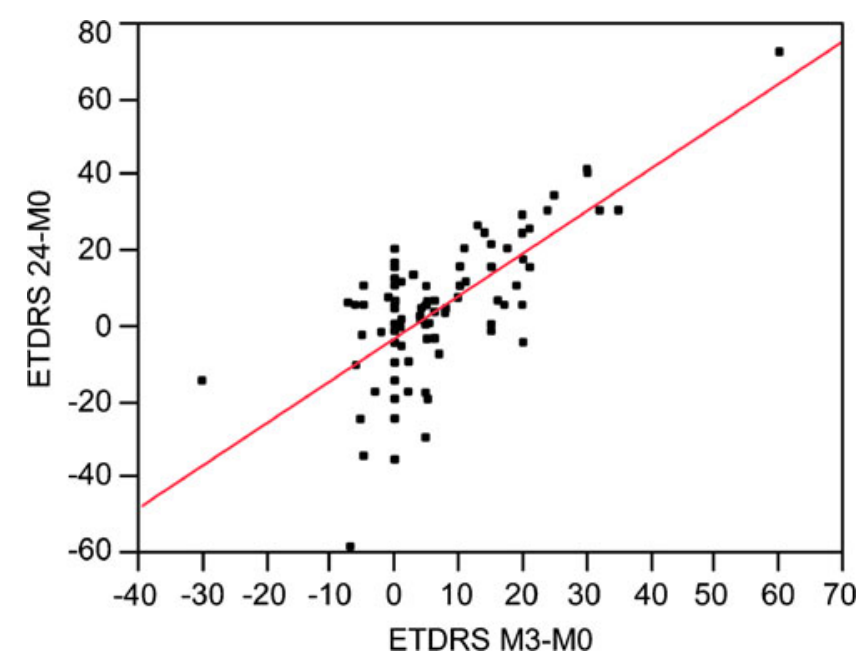

Fig. 2 Correlation between visual acuity change after initial three injections of ranibizumab and final visual acuity change. Bivariate fit of ETDRS letter score change at last visit, up to month 24, by letter score change at month 3 (as compared to baseline letter score). Mathematical equation: (ETDRS M24-M0) $=-3.29+1.12 *($ ETDRS M3-M0). Pearson correlation coefficient $r=0.52, p<0.01$ were maintainers and that 30 were losers. Mean follow-up duration was 21.2 months in the maintainer group, and 22.0 months in the loser group. Mean baseline BCVA was 61 letters (SD 16) in the loser group, and 58 letters (SD 15) in the maintainer group, which did not represent a significant difference. The mean BCVA curves of these two groups did diverge after month 3 but little change was found after month 12, as shown in Fig. 3a. Most losers were assigned to their category by month 12 ( 25 out of 30 ). The remaining five eyes changed their category after month 12 with mild VA loss only, while eight other eyes were transiently in the loser category by month 12 , recovering thereafter. Losers showed a mean VA improvement from baseline of +5.8 letters (SD 8.5) at month 3, a mean VA loss from baseline of -5.3 letters (SD 10.2) at month 12, and a loss of -9.7 (SD 9.9) at the final visit, up to month 24 (mean secondary visual loss was -16.5 letters, SD 12.5). The 69 patients who maintained their vision showed a mean gain of +8.9 letters (SD 13.4) at month $3 ;+10.4$ letters (SD 9.5 ) at month 12 and a gain of +12.8 letters (11.3) at the final visit (mean secondary visual change was a gain of +4.4 letters (SD 7.2). In terms of mean CRT, there was a mild statistically insignificant, difference, with slightly thicker central retinal subfields seen on OCT in the group of visual acuity losers (Fig. 3b). However, this curve did not reflect individual variations in retinal thickness as this disappeared in the averaged values. VA maintainers showed a mean CRT excess (after month 3) of $55 \mu \mathrm{m}$ (SD 32), while VA losers had a mean excess of $61 \mu \mathrm{m}$ (SD 48) (statistically insignificant, Table 1). In all eyes, the fluid had disappeared completely at the time of their best anatomic response, except for one patient in the loser group who had persistent subretinal fluid despite monthly treatment. The number of injections per year was similar in both groups (secondary losers: mean 7.8 injections, SD 2.0, in year 1 and 6.5 injections, SD 2.2, in year 2 for those reaching 24 months; maintainers: mean 7.7 injections, SD 2.1, in year 1 and 6.3 injections, SD 2.3, in year 2 for those reaching 24 months). Table 1 provides an overview of the statistical analyses, which showed no significant differences in initial VA response, mean CRT excess or number of injections during the maintenance phase.

Baseline characteristics that are known to be associated with the overall functional outcome of ranibizumab treatment (age, lesion size, VA at baseline, VA change after 3 months) and did not show any association with the subgroup of patients who experienced secondary loss of VA. There were significantly more patients with PED in the loser group (ten of 30 patients) than in the maintainer group (eight of 69 patients), with a $p$ value of 0.01 (Fisher's exact test, Table 1). Of the eight cases of PED in the loser group, six were found in occult lesions (three fibrovascular, three serous), and two were present in patients with retinal 

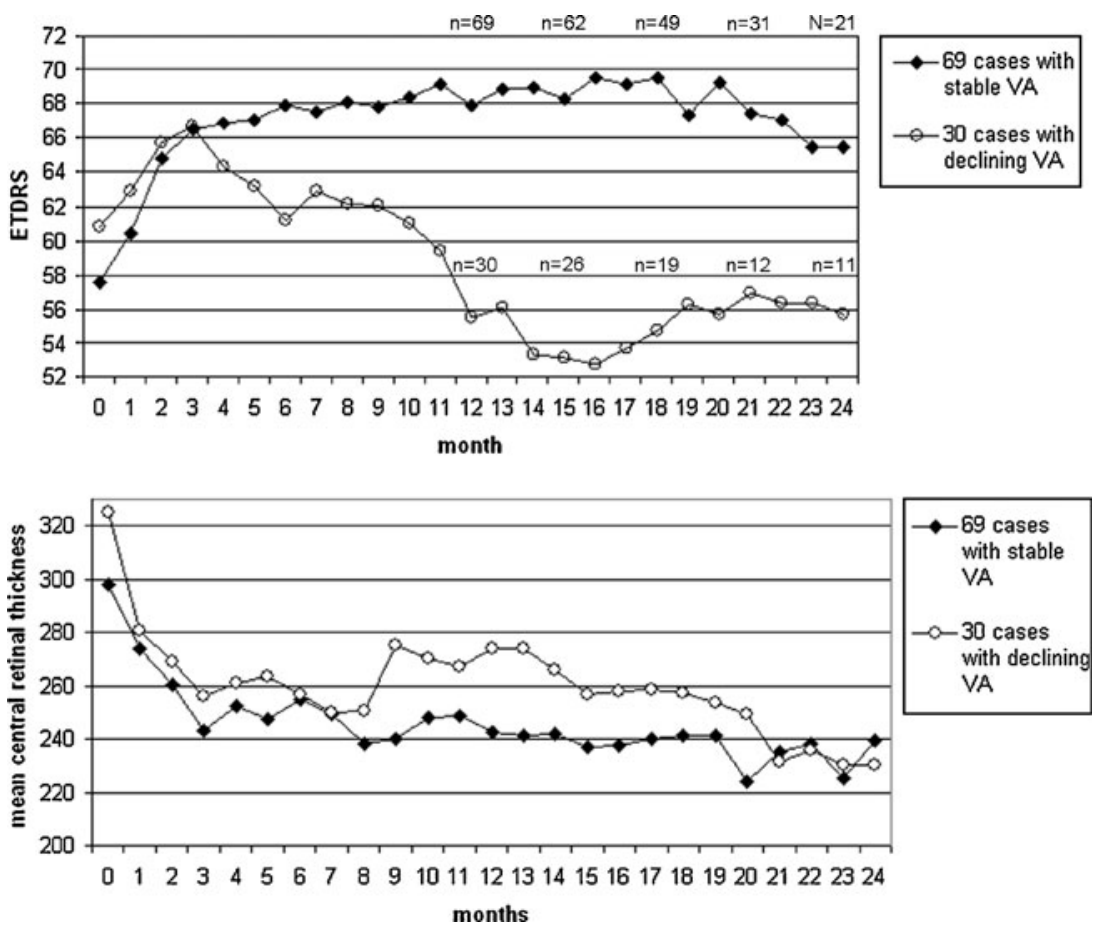

Fig. 3 Mean visual acuity curves and mean central retinal thickness curves in subgroups of secondary visual acuity maintainers and losers. a Mean visual acuity curve (ETDRS letter score) of the subgroups: Visual acuity maintainers were those patients treated with ranibizumab for exudative age-related macular degeneration who maintained bestcorrected visual acuity or lost a maximum of four letters at last observation (or until month 24) as compared with month 3 . The group of secondary visual acuity losers was defined as those who lost five or more letters after month 3 . The number of patients who completed 12 , $15,18,21$, and 24 months, respectively, are indicated $(n)$. The curves

angiomatous proliferation (two serous). Seven of the eight patients with PED had been assigned to the secondary loser category by month 12 . However, distribution by angiographic lesion type was similar in both groups (Chi-square test: predominantly classic $\mathrm{CNV}, p=0.61$; minimally classic $\mathrm{CNV}, p=0.28$; occult $\mathrm{CNV}, p=0.16$; retinal angiomatous proliferation, $p=0.12$ ). Furthermore, the presence or absence of central atrophy, fibrosis, or hemorrhage at baseline (which were inclusion/exclusion criteria of the MARINA and ANCHOR studies) did not show any association with the subgroups (eight patients in the maintainer group, five patients in the loser group).

Multiple linear regression analysis was performed, with the difference between VA at month 3 and at last visit (or until month 24) as the continuous parameter. Presence of PED at baseline was the only factor that remained significant of poorer outcome $(p=0.02)$.

A systematic review of the medical records of group B patients (which consisted of the 30 VA losers) revealed, for each individual, a viable explanation for the decline in VA after month 3 (Table 2). Major secondary VA loss diverged between months 3 and 12, which corresponded to the early phase of the variable dosing regimen after the initial loading doses of ranibizumab. b Mean central retinal thickness curves in microns of mean values for the central retinal subfield on optical coherence tomography of the subgroups as described for Fig. 3a. There was a mild statistically insignificant difference with slightly thicker central retinal subfields on optical coherence tomography in the group of visual acuity losers. This curve does not, however, reflect individual variations in retinal thickness as these disappear in averaged values

occurred in patients with massive hemorrhage during follow-up and in those with a retinal pigment epithelial (RPE) tear (four patients with PED, two patients without PED at baseline), followed by RPE degeneration in patients with PED, and foveal atrophy and subfoveal fibrosis that developed during follow-up. Minor secondary VA loss occurred in cases with strong recurrence of exudation, persistent subretinal fluid despite monthly treatment, and cataract progression.

\section{Discussion}

Intravitreal ranibizumab is currently the "gold standard" of treatment for nAMD, primarily because of its welldocumented efficacy and safety [1-3]. However, the response of VA varies greatly from one individual to another. Several factors for functional outcome have been identified [9-11], but the initial functional response after the first three injections appears to be particularly predictive of the long-term result, both in our study and in other reports 
Table 1 Statistical analysis of factors potentially involved in secondary visual acuity loss (during maintenance phase) in patients with exudative age-related macular degeneration treated with variable dosage intravitreal ranibizumab

\begin{tabular}{|c|c|c|c|}
\hline & $\begin{array}{l}\text { VA maintainers } \\
n=69\end{array}$ & $\begin{array}{l}\text { Secondary VA } \\
\text { losers } \\
n=30\end{array}$ & $p$ \\
\hline $\begin{array}{l}\text { Initial VA change after } \\
\text { 3-monthly loading } \\
\text { doses }\end{array}$ & $+8.9(\mathrm{SD} 13.4)$ & $+5.8(\mathrm{SD} 8.5)$ & 0.58 n.s. \\
\hline $\begin{array}{l}\text { Mean CRT excess } \\
\text { after month } 3\end{array}$ & $55 \mu \mathrm{m}(\mathrm{SD} 32)$ & $61 \mu \mathrm{m}(\mathrm{SD} 48)$ & 0.76 n.s. \\
\hline \multirow{2}{*}{$\begin{array}{l}\text { Number of injections } \\
\text { during years } 1 \text { and } 2\end{array}$} & 7.8. (SD 2.0) & 7.7 (SD 2.1) & $0.82 \mathrm{n} . \mathrm{s}$. \\
\hline & 6.5 (SD 2.2) & $6.3(\mathrm{SD} 2.3)$ & $0.75 \mathrm{n} . \mathrm{s}$. \\
\hline Presence of PED & $8(11.6 \%)$ & $10(33.3 \%)$ & 0.01 \\
\hline \multirow{4}{*}{$\begin{array}{l}\text { Angiographic lesion } \\
\text { type at baseline }\end{array}$} & $\mathrm{pc}=17(24.6 \%)$ & $\mathrm{pc}=6(20.0 \%)$ & $0.61 \mathrm{n} . \mathrm{s}$. \\
\hline & $\mathrm{occ}=36(52.2 \%)$ & $\mathrm{occ}=11(36.7 \%)$ & 0.16 n.s. \\
\hline & $m c=3(4.3 \%)$ & $\mathrm{mc}=3(10.0 \%)$ & $0.28 \mathrm{n} . \mathrm{s}$. \\
\hline & $\mathrm{RAP}=13(18.8 \%)$ & $\mathrm{RAP}=10(33.3 \%)$ & $0.12 \mathrm{n} . \mathrm{s}$ \\
\hline $\begin{array}{l}\text { Presence of fibrosis/atrophy/ } \\
\text { hemorrhage at baseline }\end{array}$ & $8(11.6 \%)$ & $5(16.7 \%)$ & 0.19 n.s. \\
\hline
\end{tabular}

n.s. not significant; $S D$ standard deviation; $V A$ visual acuity; $C R T$ central retinal thickness; $P E D$ pigment epithelial detachment; $p c$ predominantly classic neovascular membrane; occ occult neovascular membrane; $m c$ minimally classic neovascular membrane; $R A P$ retinal angiomatous proliferation

in the literature [11], possibly indicative of the remaining functional potential of the surviving retinal cells.

The PIER study has shown that less than monthly treatment (fixed 3-monthly treatments) results in secondary loss of the initial VA gain in a subgroup of patients ("gain

Table 2 Individual clinical causes of secondary visual decline of five letters or more during maintenance phase in patients with exudative age-related macular degeneration treated with variable dosage intravitreal ranibizumab, by degree of secondary visual loss

\begin{tabular}{|c|c|c|c|}
\hline Cause & $n$ & $\begin{array}{l}\text { Mean visual acuity } \\
\text { change from month } 3\end{array}$ & $\begin{array}{l}\text { Mean visual acuity } \\
\text { change from } \\
\text { baseline }\end{array}$ \\
\hline $\begin{array}{l}\text { Massive hemorrhage } \\
\text { occurring during } \\
\text { follow-up }\end{array}$ & 2 & -44 & -47 \\
\hline $\begin{array}{l}\text { Pigment epithelial tear } \\
\text { occurring during } \\
\text { follow-up }\end{array}$ & 6 & -26 & -23 \\
\hline $\begin{array}{l}\text { Pigment epithelial detachment } \\
\text { degeneration }\end{array}$ & 5 & -18 & -9 \\
\hline $\begin{array}{l}\text { Foveal atrophy developing } \\
\text { during follow-up }\end{array}$ & 7 & -13 & -7 \\
\hline $\begin{array}{l}\text { Subfoveal fibrosis developing } \\
\text { during follow-up }\end{array}$ & 7 & -10 & 0 \\
\hline Persistent subfoveal fluid & 1 & -7 & -6 \\
\hline Cataract progression & 1 & -5 & -5 \\
\hline $\begin{array}{l}\text { Rapid recurrence with } \\
\text { strong exudation }\end{array}$ & 1 & -5 & 0 \\
\hline Total & 30 & $-16.5(\mathrm{SD} 12.5)$ & $-9,7$ (SD 9.9) \\
\hline
\end{tabular}

and not maintain"), in contrast with another subgroup of patients, which was termed "gain and maintain" [5, 6].

The purpose of the present study was to identify the subgroup of eyes responsible for the secondary VA decline of the mean VA curve, and to identify associated characteristics. A small set of baseline characteristics was examined (PED, fibrosis, atrophy, hemorrhage), as were some factors related to the variable dosing regimen (CRT fluctuations, number of injections).

PED at baseline was associated with statistically increased risk of secondary VA loss after month 3, an effect that was independent of the functional response at month 3. In the large MARINA and ANCHOR trials, although cases of nAMD with PED could potentially be included, they were not reported separately. However, a recent subgroup analysis of patients with moderate to severe visual loss despite monthly anti-VEGF treatment found an increased incidence of RPE tears in those with poor outcome as compared with those with no visual loss or only mild visual loss, while no difference was found in the baseline area of serous PED [12]. A retrospective study of patients with different subfoveal CNV types, including a group with PED, did not find any difference in short-term VA results (7 months) [13]. However, many reports have been published about the risk of RPE tears, which are present in about $13-17 \%$ of nAMD cases with PED [14-17], but which are seen also in the absence of PED [18, 19]. Height and extension of the PED have also been reported to be major risk factors [14, 15]. A tear of the RPE can cause significant loss of VA despite VEGF suppression, if the fovea is involved [16]. Our finding that PED may be associated with secondary visual loss after month 3 included some cases of RPE tears as well as progressive RPE degeneration (Table 2).

An association with follow-up parameters such as CRT fluctuations or number of injections per year could be expected, because these parameters may reflect insufficient treatment in the group of secondary losers. The EXCITE study showed retinal thickness fluctuations that were of major importance in the "gain and not maintain" (and "no initial gain") subgroup, suggesting a causal association with the loss of VA after month 3 (data on file, Novartis Pharma AG, Basel, Switzerland; presented at the SOE Congress of the European Society of Ophthalmology, Amsterdam, 2009, Prünte et al., on behalf of the EXCITE study group). Thus, recurrent retinal exudation might be associated with slow loss of BCVA. The variable dosing regimen typically requires some signs of exudation (fluid on OCT, exudation on FA or hemorrhage on fundus examination) to reappear before the patient is re-treated. Thus, during each pretreatment period, some damage to the retinal cells may theoretically occur, which might ultimately translate to irreversible functional loss of vision. A meta-analysis has 
shown that all variable dosing regimens tend to result in a partial loss of the initial effect (similar to our finding), while fixed monthly dosing results in a slight increase in VA after month 3 [6]. More recent studies evaluating the variable dosing with ranibizumab have confirmed the same trend: functional results at 12 or 24 months are always slightly lower than at month 3 [20-23] Furthermore, most of these variable dosing regimens result in lower VA gain at month 12 than would be expected from the MARINA and ANCHOR studies [21, 24-27]. However, despite the overall trend of losing some of the gained visual acuity, some reports have shown relatively good outcomes of the variable dosing regimen $[8,22,23]$.

Recently, Gerding et al. reported a retrospective evaluation that showed a correlation between functional loss of VA and a preceding increase in CRT. This loss of VA was only partially reversible, and led, in some patients, to a permanent functional loss [20]. In a similar way, we chose to analyze CRT changes. In the present study, we used averaged values of the individual changes from the thinnest ever measured CRT, assuming that the smallest value represented the best anatomical outcome, and that any higher value was due to liquid (CRT excess). We, however, did not find an association of secondary visual loss with individual CRT fluctuations or with the number of injections. There are several possible explanations for this: The retinal CRT variations in our sample are relatively moderate, as we re-treated at thickness increases of $50 \mu \mathrm{m}$ (compared to $100 \mu \mathrm{m}$ in the PrONTO study [8]) or even before if other signs of fluid were present on OCT. With such mild fluid fluctuations, a larger sample size might be needed to show an effect on functional outcome. However, as a general rule, clinical relevance decreases progressively with increasing number of subjects needed in order to show a statistically significant difference. In addition, there are significant shortcomings of the Stratus OCT in reproducibly quantifying retinal thickness, and segmentation errors frequently occur [28]. Patients with reduced VA may have difficulty with fixation, and central measurement may have to be manually adjusted, resulting potentially in suboptimal centralization. The goal of the manual correction used in our study was to reduce this problem, although it is not possible to completely correct this error. Well-designed studies with OCT instruments that more precisely perform these measurements are needed to better investigate to what degree CRT fluctuations might cause secondary VA loss in the variable dosing regimen.

The number of injections was similar in the "loser" and the "maintainer" groups. In the literature, a trend of lower efficacy of ranibizumab has been reported in the series with fewer re-treatments, particularly if less than five injections per year were given $[26,29]$. It has been calculated that 8.4 injections, on average, might be needed to stabilize visual acuity after month 3 [20]. Our series did not show less effect with fewer treatments, which might be a consequence of our very early re-treatment criteria, which results in a relatively high mean number of re-treatments (an average of 7.8 injections in the first year, and 6.4 injections in the second year).

The case-by-case chart review of all secondary losers revealed additional individual explanations for VA loss. Besides the discussed RPE tears and RPE degeneration with persistent PED, there were cases of massive subretinal hemorrhage that caused secondary loss of VA, and mild secondary VA loss was found to be due to foveal atrophy or fibrosis that developed during follow-up. Any of these events could potentially occur, even under complete VEGF suppression, such as with a monthly regimen of ranibizumab [12]. In the MARINA and ANCHOR studies, approximately $5-10 \%$ of patients had moderate to severe visual acuity loss (more than 3 lines from baseline) despite continuous blocking of VEGF [1-3], although subgroup analysis revealed an association with lesion characteristics commonly associated with suppressed CNV, such as pigmentary abnormalities and progression of the atrophic scar, in the absence of leakage [12]. Thus, we agree with the conclusion that photoreceptor and RPE damage may be major factors for long- term loss of VA despite VEGF suppression, and future improvements in VA of patients receiving ranibizumab therapy may require preservation of photoreceptor and RPE cells rather than targeting the CNV [12].

In conclusion, tissue damage due to PED degeneration, RPE tears, progressive fibrosis, progressive atrophy, or massive hemorrhage, appears to be relevant in causing secondary loss of VA despite VEGF suppression, and presence or absence of PED at baseline may be an important risk factor. A variable dosing regimen with ranibizumab allows overall functional results similar to those with monthly treatment; at least if the patient is monitored with monthly visits and if early re-treatment criteria are in place. However, further studies are warranted to identify the impact of CRT fluctuations during a variable dosing regimen with ranibizumab for nAMD.

Funding None.

Financial disclosure None.

\section{References}

1. Brown DM, Kaiser PK, Michels M, Soubrane G, Heier JS, Kim RY, Sy JP, Schneider S (2006) Ranibizumab versus verteporfin for 
neovascular age-related macular degeneration. $\mathrm{N}$ Engl J Med 355:1432-1444

2. Brown DM, Michels M, Kaiser PK, Heier JS, Sy JP, Ianchulev T (2009) Ranibizumab versus verteporfin photodynamic therapy for neovascular age-related macular degeneration: two-year results of the ANCHOR study. Ophthalmology 116:57-65

3. Rosenfeld PJ, Brown DM, Heier JS, Boyer DS, Kaiser PK, Chung CY, Kim RY (2006) Ranibizumab for neovascular age-related macular degeneration. N Engl J Med 355:1419-1431

4. Abraham P, Yue H, Wilson L (2010) Randomized, double-masked, sham-controlled trial of ranibizumab for neovascular age-related macular degeneration: PIER study year 2. Am J Ophthalmol 150:315-324

5. Regillo CD, Brown DM, Abraham P, Yue H, Ianchulev T, Schneider S, Shams N (2008) Randomized, double-masked, sham-controlled trial of ranibizumab for neovascular age-related macular degeneration: PIER Study year 1. Am J Ophthalmol 145:239-248

6. Mitchell P, Korobelnik JF, Lanzetta P, Holz FG, Prunte C, SchmidtErfurth U, Tano Y, Wolf S (2010) Ranibizumab (Lucentis) in neovascular age-related macular degeneration: evidence from clinical trials. Br J Ophthalmol 94:2-13

7. Schmidt-Erfurth U, Eldem B, Guymer R, Korobelnik JF, Schlingemann RO, Axer-Siegel R, Wiedemann P, Simader C, Gekkieva M, Weichselberger A (2011) Efficacy and safety of monthly versus quarterly ranibizumab treatment in neovascular age-related macular degeneration The EXCITE Study. Ophthalmology 118:831-839

8. Fung AE, Lalwani GA, Rosenfeld PJ, Dubovy SR, Michels S, Feuer WJ, Puliafito CA, Davis JL, Flynn HW Jr, Esquiabro M (2007) An optical coherence tomography-guided, variable dosing regimen with intravitreal ranibizumab (Lucentis) for neovascular age-related macular degeneration. Am J Ophthalmol 143:566-583

9. Boyer DS, Antoszyk AN, Awh CC, Bhisitkul RB, Shapiro H, Acharya NR (2007) Subgroup analysis of the MARINA study of ranibizumab in neovascular age-related macular degeneration. Ophthalmology 114:246-252

10. Kaiser PK, Brown DM, Zhang K, Hudson HL, Holz FG, Shapiro H, Schneider S, Acharya NR (2007) Ranibizumab for predominantly classic neovascular age-related macular degeneration: subgroup analysis of first-year ANCHOR results. Am J Ophthalmol 144:850-857

11. Menghini M, Kurz-Levin MM, Amstutz C, Michels S, Windisch R, Barthelmes D, Sutter FK (2010) Response to ranibizumab therapy in neovascular. Klin Monbl Augenheilkd 227:244-248

12. Rosenfeld PJ, Shapiro H, Tuomi L, Webster M, Elledge J, Blodi B (2011) Characteristics of patients losing vision after 2 years of monthly dosing in the phase III ranibizumab clinical trials. Ophthalmology 118:523-530

13. Tao Y, Jonas JB (2010) Intravitreal bevacizumab for exudative age-related macular degeneration: effect on different subfoveal membranes. Retina 30:1426-1431

14. Chan CK, Meyer CH, Gross JG, Abraham P, Nuthi AS, Kokame GT, Lin SG, Rauser ME, Kaiser PK (2007) Retinal pigment epithelial tears after intravitreal bevacizumab injection for neovascular age-related macular degeneration. Retina 27:541-551

15. Chan CK, Abraham P, Meyer CH, Kokame GT, Kaiser PK, Rauser ME, Gross JG, Nuthi AS, Lin SG, Daher NS (2010) Optical coherence tomography-measured pigment epithelial detachment height as a predictor for retinal pigment epithelial tears associated with intravitreal bevacizumab injections. Retina 30:203-211
16. Kook D, Wolf A, Neubauer AS, Haritoglou C, Priglinger SG, Kampik A, Ulbig MW (2008) Retinal pigment epithelial tears after intravitreal injection of bevacizumab for AMD. Frequency and progress. Ophthalmologe 105:158-164

17. Weinberger AW, Thiel M, Mohammadi B, Theofylaktopoulos I, Thumann G, Walter P (2007) Retinal pigment epithelium tears after intravitreal bevacizumab in pigment epithelium detachment. Am J Ophthalmol 144:294-296

18. Arias L, Caminal JM, Rubio M, Pujol O, Arruga J (2007) Retinal pigment epithelial tears after intravitreal bevacizumab injection for predominantly classic choroidal neovascularization. Eur J Ophthalmol 17:992-995

19. Konstantinidis L, Ambresin A, Zografos L, Mantel I (2010) Retinal pigment epithelium tears after intravitreal injection of ranibizumab for predominantly classic neovascular membranes secondary to age-related macular degeneration. Acta Ophthalmol 88:736-741

20. Gerding H, Loukopoulos V, Riese J, Herner L, Timmermann M (2011) Results of flexible ranibizumab treatment in age-related macular degeneration and search of parameters with impact on outcome. Graefes Arch Clin Exp Ophthalmol 249:653-662

21. Heimes B, Lommatzsch A, Zeimer M, Gutfleisch M, Spital G, Dietzel M, Pauleikhoff D (2011) Long-term visual course after anti-VEGF therapy for exudative AMD in clinical practice evaluation of the German reinjection scheme. Graefes Arch Clin Exp Ophthalmol 249:639-644

22. Rothenbuehler SP, Waeber D, Brinkmann CK, Worl S, WolfSchnurrbusch UEK (2009) Effects of ranibizumab in patients with subfoveal choroidal neovascularization attributable to age-related macular degeneration. Am J Ophthalmol 147:831-837

23. Querques G, Azrya S, Martinelli D, Berboucha E, Feldman A, Pece A, Coscas G, Soubrane G, Souied E (2010) Ranibizumab for exudative age-related macular degeneration: 24-month outcomes from a single-centre institutional setting. Br J Ophthalmol 94:292296

24. Boyer DS, Heier JS, Brown DM, Francom SF, Ianchulev T, Rubio RG (2009) A Phase IIIb study to evaluate the safety of ranibizumab in subjects with neovascular age-related macular degeneration. Ophthalmology 116:1731-1739

25. Cohen SY, Dubois L, Tadayoni R, Fajnkuchen F, Nghiem-Buffet S, Ahaye-Mazza C, Guiberteau B, Quentel G (2009) Results of oneyear's treatment with ranibizumab for exudative age-related macular degeneration in a clinical setting. Am J Ophthalmol 148:409-413

26. Dadgostar H, Ventura AA, Chung JY, Sharma S, Kaiser PK (2009) Evaluation of injection frequency and visual acuity outcomes for ranibizumab monotherapy in exudative age-related macular degeneration. Ophthalmology 116:1740-1747

27. Mantel I, Zografos L, Ambresin A (2008) Early clinical experience with ranibizumab for occult and minimally classic neovascular membranes in age-related macular degeneration. Ophthalmologica 222:321-323

28. Giani A, Cigada M, Esmaili DD, Salvetti P, Luccarelli S, Marziani E, Luiselli C, Sabella P, Cereda M, Eandi C, Staurenghi G (2010) Artifacts in automatic retinal segmentation using different optical coherence tomography instruments. Retina 30:607-616

29. Gerding H (2010) Behandlung der feuchten altersabhangigen Makuladegeneration mit weniger als 12 Ranibizumab-Injektionen pro Jahr. Klin Monbl Augenheilkd 227:294-297 